\title{
The p.T191M mutation of the $C B S$ gene is highly prevalent among homocystinuric patients from Spain, Portugal and South America
}

\author{
Roser Urreizti · Carla Asteggiano · Marta Bermudez • Alfonso Córdoba • \\ Marina Szlago - Carola Grosso - Raquel Dodelson de Kremer • Laura Vilarinho • \\ Vania D'Almeida · Mercedes Martínez-Pardo · Luís Peña-Quintana · Jaime Dalmau • \\ Jaime Bernal · Ignacio Briceño · María Luz Couce · Marga Rodés • \\ Maria Antonia Vilaseca · Susana Balcells · Daniel Grinberg \\ Published online: 23 February 2007 \\ (C) The Japan Society of Human Genetics and Springer 2007
}

\section{Erratum to: J Hum Genet 51:305-313 \\ DOI 10.1007/s10038-006-0362-0}

In this article, one of the novel mutations, c.208_209+ 8 del10, was incorrectly given as c.69_70+8del10. It corresponds to patient 64 in Table 4.

The online version of the original article can be found at http:// dx.doi.org/10.1007/s10038-006-0362-0.

R. Urreizti · C. Asteggiano · S. Balcells · D. Grinberg ( $($ )

Departament de Genètica, Facultat de Biologia,

Universitat de Barcelona, Av. Diagonal, 645,

08028 Barcelona, Spain

e-mail: dgrinberg@ub.edu

C. Asteggiano - C. Grosso - R. D. de Kremer

Centro de Estudio de las Metabolopatías Congénitas,

Universidad Nacional de Córdoba, Hospital de Niños,

Córdoba, Argentina

M. Bermudez · J. Bernal · I. Briceño

Instituto de Genética Humana,

Pontificia Universidad Javeriana, Bogotá, Colombia

\section{A. Córdoba}

Depto de Fisiología y Bioquímica, Facultad de Medicina,

Universidad de Antioquia, Medellín, Colombia

M. Szlago

Fundación para el Estudio de las Enfermedades

Neurometabólicas, Buenos Aires, Argentina

\section{Vilarinho}

Instituto de Genética Médica Jacinto Magalhaes, Porto, Portugal

V. D'Almeida

Department of Pediatrics, Universidade Fereral de Sao

Paulo-UNIFESP/EPM, Sao Paulo, Brazil
Additionally, the genotype for patient 34 (Table 4) is p.T191M/p.T191M, and not p.[T191M;D444N]/ [T191M;D444N]. Accordingly, in the Discussion, the two sentences: "It should be noted that two patients in our series bore p.D444N: patient \#54 (described above) and patient \#34. The latter was homozygous for the

M. Martínez-Pardo

Unidad de Enfermedades Metabólicas,

Servicio de Pediatría, Hospital Ramón y Cajal,

Madrid, Spain

L. Peña-Quintana

Unidad de Gastroenterología y Nutrición,

Hospital Universitario Materno Infantil,

Las Palmas de GC, Spain

J. Dalmau

Unidad de Nutrición y Metabolopatías,

Hospital Infantil La Fe, Valencia, Spain

M. L. Couce

Departamento de Pediatría,

Hospital Clínico Universitario de Santiago,

Santiago de Compostela, Spain

M. Rodés

Institut de Bioquímica Clínica,

Corporació Sanitària-Clínic, Barcelona, Spain

M. A. Vilaseca

Servei de Bioquímica,

Hospital Sant Joan de Déu, Barcelona, Spain 
double-mutant allele p.[T191M;D444N]. Both patients originate from the same region of Spain." should not be taken into consideration.

Finally, the correct name of one of the authors is Dr. Marina Szlago and not Dr. Mariana Szlago.

The authors regret these mistakes. 